\title{
Antibiotic Resistance Gene Detection in the Microbiome Context
}

\author{
Thi Thuy Do, Javier Tamames, Robert D. Stedtfeld, ${ }^{2}$ Xueping Guo, \\ Sinead Murphy, James M. Tiedje, and Fiona Walsh ${ }^{1}$
}

\begin{abstract}
Within the past decade, microbiologists have moved from detecting single antibiotic resistance genes (ARGs) to detecting all known resistance genes within a sample due to advances in next generation sequencing. This has provided a wealth of data on the variation and relative abundances of ARGs present in a total bacterial population. However, to use these data in terms of therapy or risk to patients, they must be analyzed in the context of the background microbiome. Using a quantitative PCR ARG chip and 16S rRNA amplicon sequencing, we have sought to identify the ARGs and bacteria present in a fecal sample of a healthy adult using genomic tools. Of the 42 ARGs detected, 12 fitted into the ResCon1 category of ARGs: $c f x A, c p h A$, bacA, sul3, aadE, bla ${ }_{\mathrm{TEM}}$, aphAl, aphA3, aph(2')-Id, aacA/aphd, catAl, and vanC. Therefore, we describe these 12 genes as the core resistome of this person's fecal microbiome and the remaining 30 ARGs as descriptors of the microbial population within the fecal microbiome. The dominant phyla and genera agree with those previously detected in the greatest abundances in fecal samples of healthy humans. The majority of the ARGs detected were associated with the presence of specific bacterial taxa, which were confirmed using microbiome analysis. We acknowledge the limitations of the data in the context of the limited sample set. However, the principle of combining qPCR and microbiome analysis was shown to be helpful to identify the association of the ARGs with specific taxa.
\end{abstract}

Keywords: microbiome, resistome, feces, human

\section{Introduction}

$\mathbf{T}$ O MINIMIZE THE BURDEN of antibiotic resistance and to identify the areas of greatest risk to human health, we must understand how antibiotic resistance genes (ARGs) selection and proliferation occur in a complex bacterial system such as the human gut microbiome. There is not yet a consensus on the selection of ARGs and bacterial changes required for the proliferation of ARGs and increases in ARG abundances in complex bacterial populations. ${ }^{1-8}$ To understand the influence of antibiotics on mixed complex populations, such as the gut microbiome, we must first identify and understand the background or baseline resistance genes and intrinsic resistance mechanisms present in the human gut bacteria. Only then can we identify the risks and potential pathways of ARG transfer from the gut microflora to pathogenic bacteria. If an ARG identified in the gut microbiome is present on the chromosome of an anaerobe, it does not pose the same risk to the treatment of a patient as if the same gene is present on a highly mobile plasmid. Thus, the genes must be identified in their bacterial or microbiome context.
The aims of this study were to identify and measure the relative abundances of ARGs and bacteria present in a fecal sample of a healthy adult using molecular biology tools. As we move further toward genomic analysis of ARGs and bacteria, we must generate guidelines for the interpretation of the data generated. To do this, we must understand which bacteria and ARGs are present in the healthy human and then what constitutes a risk to the treatment of a patient in terms of likelihood of transfer to pathogenic bacteria.

\section{Materials and Methods}

\section{Sample preparation and DNA extraction}

A fecal sample was collected from a healthy adult who had taken no antibiotics in the previous 2 years. It was immediately homogenized and $0.6 \mathrm{~g}$ was added directly to the MoBio $^{\mathrm{TM}}$ Power Soil ${ }^{\circledR}$ DNA isolation kit tube in step one of the protocol. The DNA was extracted using the kit protocol.

The NUI Maynooth Biomedical and Life Sciences Research Ethics Sub-Committee approved this study and

\footnotetext{
${ }^{1}$ Department of Biology, Maynooth University, Maynooth, Ireland.

${ }^{2}$ Spanish National Centre for Biotechnology, Madrid, Spain.

${ }^{3}$ Department of Civil and Environmental Engineering, Michigan State University, East Lansing, Michigan.

${ }^{4}$ Center for Microbial Ecology, Michigan State University, East Lansing, Michigan.
} 
experimental protocols (application reference number BRSERC-2014-007). All methods were performed in accordance with ethical guidelines and regulations. Written informed consent was obtained from the subject.

\section{S rRNA amplicon sequencing}

The V3 and V4 regions of the 16S rRNA genes were amplified and sequenced using the Illumina MiSeq ${ }^{\circledR}$ primers and protocol. ${ }^{9}$ A $2 \times 150$ paired-end configuration was used for sequencing. The image analysis and base calling were processed using MiSeq Control Software. The data were quality control checked and trimmed and analyzed initially using the Illumina BaseSpace app. ${ }^{10}$ The sequencing data were processed using Quantitative Insights Into Microbial Ecology version 1.5.0. ${ }^{11}$ Shannon diversity, collectors curve, and Chao-1 were used to determine the evenness of the $16 \mathrm{~S}$ rRNA results. ${ }^{12}$

\section{$A R G$ relative abundance ( $q P C R)$}

DNA extracted from the fecal samples was used to analyze the relative abundances of the ARGs using a highly parallel quantitative PCR (qPCR) platform (Wafergen Smartchip). ${ }^{13}$ The samples analyzed comprised three biological replicates for each sample and three technical replicates of each biological replicate. The samples were analyzed for the relative abundance of 384 primer sets targeting known ARGs and mobile genetic elements (Supplementary Table S1; Supplementary Data are available online at www.liebertpub.com/mdr). The $C_{t}$ values of each primer pair were normalized using the $16 \mathrm{~S}$ rRNA gene values (deltaC $\left.\mathrm{C}_{\mathrm{t}}=\mathrm{C}_{\mathrm{t}} \mathrm{ARG}-\mathrm{C}_{\mathrm{t}} 16 \mathrm{SrRNA}\right)$. Results with a $C_{t}$ value of $>28$ were removed. The deltaC $C_{t}$ values and fold change were calculated according to Relative Gene Expression Data Using Real-Time Quantitative PCR and the deltadeltaC $\mathrm{C}_{\mathrm{t}}$ method. ${ }^{14}$ The SmartChip has been validated by comparison with metagenomics. ${ }^{15}$

\section{Results}

\section{$A R G$ resistome}

Forty-two different ARGs (plus six mobile elements and two repressor genes) were detected in the fecal sample (Table 1). Using the definitions of ARGs provided by Martinez et al. would exclude efflux genes, ampC genes, the erythromycin resistance genes, and the tetracycline resistance genes as these are not considered ARGs from an ecological viewpoint. ${ }^{16}$ The erythromycin and tetracycline resistance genes are frequently identified on the chromosomes of anaerobes commonly found in the human gut microbiome and are not considered to confer resistance in these bacteria. Their presence identified the bacteria harboring these genes, rather than a resistance reservoir. Of the 42 ARGs detected, 12 fitted into the ResCon1 category of ARGs as defined by Martinez et al. ${ }^{16}$ These were ARGs cfxA, cphA, bacA, sul3, aadE, aphA1, aphA3, aph(2')-Id, aacA/ aphd, bla $a_{\mathrm{TEM}}, c a t A 1$, and $v a n C$. Therefore, we describe these 12 genes as the core resistome of this person's fecal microbiome and the remaining 30 ARGs as descriptors of the microbial population within the fecal microbiome.

\section{Relative abundances of genes}

The relative abundances of each ARG were determined by comparison with the $16 \mathrm{~S}$ rRNA gene abundance. This en- sured that variations in DNA quantities were not responsible for variations in the ARG abundances in the sample (Table 1). The genes with the highest relative abundances comprised mobile genetic elements (insertion sequences and transposases), tetracycline and erythromycin resistance genes associated with the anaerobes present in the human gut microbiome, and the $c f x A$ beta-lactamase gene. The genes detected in the lowest relative abundances comprised efflux genes (tet $C$, ceoA, and tetB), a tetracycline resistance gene regulator (tetR), vanC, mobile genetic elements (IncN and $p N I 105)$, beta-lactamase $\left(b l a_{\mathrm{TEM}}\right)$, aminoglycoside (aacA/ aphd), and chloramphenicol (catAl) resistance genes.

\section{Bacterial community analysis using 16S rRNA gene amplicon sequencing}

Microbial composition. The phyla, which constituted the taxa at $>1 \%$ within the 89303 OTU sequence reads, that passed the quality control filtering comprised Firmicutes (66\%), Bacteroidetes (28\%), Proteobacteria (2.5\%), unclassified (1.5\%), and Actinobacteria (1.2\%). The dominant phyla are consistent with previous findings. ${ }^{16}$ Within these phyla, the taxa were spread across 32 classes, with 6 of those representing $>1 \%$ relative abundances: Clostridia (65\%), Bacteroidia (20\%), Flavobacteria (7.3\%), unclassified (2\%), Actinobacteria (1.2\%), and Bacilli (1\%). The classes were subdivided into 68 orders with Clostridiales (64\%), Bacteroidales (20\%), Flavobactriales (7.3\%), and unclassified (2.3\%), representing those at $>1 \%$. The families within the microbiome $(n=143)$ at $>1 \%$ were represented by Lachnospiraceae (32\%), Ruminococcaceae (25\%), Bacteroidaceae (11\%), Flavobacteriaceae $(7.3 \%)$, unclassified $(4.6 \%)$, Clostridiaceae (3.8\%), Paraprevotellaceae $(3.7 \%)$, Odoribacteraceae $(2.7 \%)$, Porphyromonadaceae (2.2\%), and Eubacteriaceae (1.6\%). A total of 263 different genera were represented in the fecal microbiome and those with $>1 \%$ relative abundance comprised 19 different genera (including unclassified), which represented $90 \%$ of the total microbiome composition (Table 2). Dominant genera also agree with those previously detected in the greatest abundances in fecal samples of a healthy human. ${ }^{17}$ Although correlations between bacterial phylogenies and antibiotic resistomes have been reported by Pehrsson et al., this was using diverse habitats. ${ }^{18}$

\section{Discussion}

In a mixed bacterial population, such as human feces, bacteria are present that contain ARGs either on their chromosomes or on mobile elements. These bacteria are maintained within the fecal population due to their roles, regardless of the ARG or selective antibiotic pressures. With advances in next generation sequencing (NGS) came studies measuring the influences of antibiotics on complex bacterial populations and their total antibiotic resistomes, such as the human gut microbiome. ${ }^{1-8}$ However, to identify the changes occurring within a population of bacteria, we must first identify the ARGs present in the natural fecal bacterial population, independent of selective pressure. With reduced cost and increased capacity, NGS has become a potential tool for the identification of ARGs and pathogens directly from patients. In order for such technology to function, one must understand the difference between carriage and selection of bacterial species and ARGs. This study aimed to 
Table 1. Relative Abundances of Antibiotic Resistance Genes Detected Using the Quantitative PCR ChiP

\begin{tabular}{|c|c|c|c|c|c|c|c|}
\hline Primer name & Role & $\begin{array}{l}\text { Antibiotic } \\
\quad \text { class }\end{array}$ & $\begin{array}{l}\text { Average } \\
\text { Ct value }\end{array}$ & $\begin{array}{l}\text { Standard } \\
\text { deviation } \\
\text { of Ct } \\
\text { values }\end{array}$ & $\begin{array}{l}\text { Relative } \\
\text { abundances } \\
\text { ranked high } \\
\quad \text { to low }\end{array}$ & $\begin{array}{c}\text { Example of } \\
\text { fecal bacteria } \\
\text { harboring gene } \\
\text { on chromosome }\end{array}$ & $\begin{array}{c}\text { Family } \\
\text { present } \\
\text { in sample }\end{array}$ \\
\hline $16 \mathrm{~S}$ rRNA & 16S rRNA & & 12.53 & 0.110 & & & \\
\hline IS613 & MGE & $\begin{array}{l}\text { Insertion } \\
\text { sequence }\end{array}$ & 15.90 & 0.109 & 0.096722812 & & \\
\hline tet $Q$ & Protection & Tetracycline & 16.71 & 0.155 & 0.055168937 & Bacteroides fragilis & Bacteroidaceae \\
\hline tet $W$ & Protection & Tetracycline & 16.81 & 0.146 & 0.051474439 & $\begin{array}{l}\text { Bifidobacterium } \\
\text { longum }\end{array}$ & Bifidobacteriaceae \\
\hline tet $O$ & Protection & Tetracycline & 16.92 & 0.149 & 0.0476956 & $\begin{array}{c}\text { Clostridium } \\
\text { colicanis }\end{array}$ & Clostridiaceae \\
\hline Tp614 & MGE & Transposase & 17.17 & 0.222 & 0.040107059 & & \\
\hline$c f x A$ & Deactivate & Beta lactam & 17.75 & 0.127 & 0.02683017 & & \\
\hline ermB & Protection & MLSB & 18.41 & 0.143 & 0.016980232 & $\begin{array}{l}\text { Clostridium } \\
\text { perfringens }\end{array}$ & Clostridiaceae \\
\hline ermF & Protection & MLSB & 18.89 & 0.211 & 0.012174447 & Eubacterium spp. & Eubacteriaceae \\
\hline tetx & Deactivate & Tetracycline & 20.32 & 0.087 & 0.004518313 & $\begin{array}{l}\text { Flavobacterium } \\
\text { spp. }\end{array}$ & Flavobacteriaceae \\
\hline mefA & Efflux & MLSB & 20.48 & 0.174 & 0.004044004 & & \\
\hline $\operatorname{tet}(32)$ & Protection & Tetracycline & 20.54 & 0.155 & 0.003879268 & Unknown & \\
\hline ISEfm1-Entero & MGE & $\begin{array}{l}\text { Insertion } \\
\text { sequence }\end{array}$ & 22.00 & 0.102 & 0.001410087 & & \\
\hline $\operatorname{tnp} A$ & MGE & Transposase & 22.19 & 0.157 & 0.00123609 & & \\
\hline sulIII-marko & Protection & Sulfonamide & 22.91 & 0.025 & 0.000750427 & & \\
\hline $\mathrm{matA} / \mathrm{mel}$ & Efflux & MLSB & 23.23 & 0.066 & 0.000601145 & & \\
\hline $\operatorname{aphA3}$ & Deactivate & Aminoglycoside & 23.40 & 0.179 & 0.000534323 & & \\
\hline tetM & Protection & Tetracycline & 23.43 & 0.064 & 0.000523327 & $\begin{array}{l}\text { Streptococcus } \\
\quad \text { mutans }\end{array}$ & Streptococcaceae \\
\hline sat4 & Efflux & MDR & 23.47 & 0.095 & 0.000509016 & & \\
\hline $\operatorname{aph}\left(2^{\prime}\right)-I d$ & Deactivate & Aminoglycoside & 23.94 & 0.033 & 0.000367492 & & \\
\hline ermT & Protection & MLSB & 24.60 & 0.073 & 0.000232578 & $\begin{array}{l}\text { Streptococcus } \\
\quad \text { pyogenes }\end{array}$ & Streptococcaceae \\
\hline$m s r C$ & Efflux & MLSB & 24.67 & 0.237 & 0.000221562 & & \\
\hline ampC & Deactivate & Beta lactam & 24.71 & 0.44 & 0.000215504 & Pseudomonas spp. & Pseudomonadaceae \\
\hline $\mathrm{mdtF}$ & Efflux & MDR & 24.81 & 0.376 & 0.000202471 & & \\
\hline tet $L$ & Efflux & Tetracycline & 24.84 & 0.384 & 0.000196934 & & \\
\hline$y i d Y / m d t L$ & Efflux & Amphenicol & 24.90 & 0.251 & 0.000188912 & & \\
\hline bacA & Deactivate & other & 25.03 & 0.127 & 0.000172633 & Escherichia coli & Enterobacteriaceae \\
\hline $\operatorname{aad} E$ & Deactivate & Aminoglycoside & 25.46 & 0.449 & 0.000128139 & $\begin{array}{l}\text { Streptococcus } \\
\text { anginosus }\end{array}$ & Streptococcaceae \\
\hline $\operatorname{acr} F$ & Efflux & MDR & 25.52 & 0.242 & 0.000122919 & & \\
\hline yceL/mdtH & Efflux & MDR & 25.55 & 0.320 & 0.00012039 & & \\
\hline acrR & Regulator & MDR & 25.57 & 0.283 & 0.000118732 & & \\
\hline yceE/mdtG & Efflux & MDR & 25.61 & 0.362 & 0.000115486 & & \\
\hline$a c r B$ & Efflux & MDR & 25.72 & 0.502 & 0.000107008 & & \\
\hline aphA1 & Deactivate & Aminoglycoside & 25.75 & 0.312 & 0.000104805 & & \\
\hline$m d t E / y h i U$ & Efflux & MDR & 25.83 & 0.336 & 9.91519E-05 & & \\
\hline tet $P B$ & Protection & Tetracycline & 25.92 & 0.129 & $9.31555 \mathrm{E}-05$ & C. perfringens & Clostridiaceae \\
\hline $\operatorname{acr} A$ & Efflux & MDR & 26.02 & 0.442 & 8.69171E-05 & & \\
\hline cphA & Deactivate & Beta lactam & 26.06 & 0.178 & 8.45404E-05 & & \\
\hline tetPA & Efflux & Tetracycline & 26.14 & 0.412 & 7.99801E-05 & & \\
\hline $\operatorname{bex} A$ & Efflux & MDR & 26.27 & 0.207 & 7.30883E-05 & & \\
\hline tolC & Efflux & MDR & 26.82 & 0.158 & 4.99208E-05 & & \\
\hline tet $B$ & Efflux & Tetracycline & 26.82 & 0.179 & 4.99208E-05 & & \\
\hline catA1 & Deactivate & Amphenicol & 26.87 & 0.201 & 4.82203E-05 & & \\
\hline pNI105map-F & MGE & $\begin{array}{l}\text { plasmid } \\
\text { replication }\end{array}$ & 27.19 & 0.136 & $3.86278 \mathrm{E}-05$ & & \\
\hline сеоA & Efflux & Amphenicol & 27.19 & 0.195 & $3.86278 \mathrm{E}-05$ & & \\
\hline tetR & Regulator & Tetracycline & 27.22 & 0.069 & 3.78329E-05 & & \\
\hline$b l a_{T E M}$ & Deactivate & Beta lactam & 27.25 & 0.521 & 3.70543E-05 & & \\
\hline aacA/aphD & Deactivate & Aminoglycoside & 27.32 & 0.206 & $3.52993 \mathrm{E}-05$ & & \\
\hline IncN_rep-1_f & MGE & $\begin{array}{l}\text { Plasmid } \\
\text { incompatibility }\end{array}$ & 27.33 & 0.422 & $3.50555 \mathrm{E}-05$ & & \\
\hline $\operatorname{van} C$ & Protection & Vancomycin & 27.34 & 0.386 & $3.48133 \mathrm{E}-05$ & & \\
\hline tet $C$ & Efflux & Tetracycline & 27.42 & 0.323 & $3.29354 \mathrm{E}-05$ & & \\
\hline
\end{tabular}

Three technical replicates were averaged to measure the $\mathrm{Ct}$ values for each primer set. MDR, multidrug resistance; MGE, mobile genetic element. 
Table 2. Microbiome Profiles of the Human Fecal Sample $(>1 \%)$ at Genera Level

\begin{tabular}{lc}
\hline Genus & \% Relative abundance \\
\hline Faecalibacterium & 20.46739751 \\
Bacteroides & 11.02874483 \\
Blautia & 8.159860251 \\
Roseburia & 8.006449951 \\
Unclassified & 7.093826635 \\
Dorea & 4.151036359 \\
Ruminococcus & 3.951714948 \\
Flavobacterium & 3.84085641 \\
Paraprevotella & 3.721039607 \\
Pseudobutyrivibrio & 3.398542042 \\
Polaribacter & 3.33135505 \\
Coprococcus & 2.032406526 \\
Oscillospira & 1.923787555 \\
Parabacteroides & 1.675195682 \\
Acetobacterium & 1.577774543 \\
Clostridium & 1.537462347 \\
Butyricimonas & 1.436681858 \\
Odoribacter & 1.294469391 \\
Lachnospira & 1.11642386 \\
\hline
\end{tabular}

integrate NGS and antibiotic resistance qPCR chip technology to describe the fecal population of bacteria and the relative abundance of their resistome in a healthy human under no antibiotic selective pressure.

The published data on the human gut microbiome alterations due to antibiotics are highly variable. To date, there have been no definite conclusions on the bacterial genera that proliferate or decrease after specific antibiotic administration. There is no consensus on whether any microbiome changes occur at all or whether intersubject variability was greater than the effects of the antibiotics administered. The first studies of the human gut microbiome tried to identify and describe the core set of bacterial taxa responsible for health and disease. However, such studies among healthy individuals revealed wide variation in the taxonomic composition of the microbiome, which prevented the discovery or identification of a core microbiome. ${ }^{19,20}$

The majority of the ARGs detected may have been associated with the presence of specific bacterial taxa. There was a high proportion of mobile genetic elements detected, which suggests high genetic mobility within the fecal microbiome and the detection of several ARGs, which are not associated with intrinsic resistance of common gut microbiome bacteria. The conclusion from this study is that although many ARGs can be detected and their abundances measured using DNA-based tools, we must put these genes in the context of the bacterial composition of the sample, in this case feces from a healthy human, to identify the genes, which pose a risk to the treatment of pathogenic infections. This study highlights the need to put DNA analysis in context and has listed several ARGs that may be present on the chromosome of the natural fecal microbiome. The conclusions may not be further extrapolated due to the small sample size.

\section{Acknowledgment}

Dr. Walsh received funding from Maynooth University for this study.

\section{Disclosure Statement}

The authors have no competing financial interests. The funding bodies did not play a role in the experiments or their interpretation.

\section{References}

1. Dethlefsen, L., S. Huse, M.L. Sogin, and D.A. Relman. 2008. The pervasive effects of an antibiotic on the human gut microbiota, as revealed by deep $16 \mathrm{~S}$ rRNA sequencing. PLoS Biol. 6:e280.

2. Sommer, M.O., G. Dantas, and G.M. Church. 2009. Functional characterization of the antibiotic resistance reservoir in the human microflora. Science 325:11281131.

3. Jakobsson, H.E., C. Jernberg, A.F. Andersson, M. SjölundKarlsson, J.K. Jansson, and L. Engstrand. 2010. Short-term antibiotic treatment has differing long-term impacts on the human throat and gut microbiome. PLoS One 5:e9836.

4. Jernberg, C., S. Löfmark, C. Edlund, and J.K. Jansson. 2010. Long-term impacts of antibiotic exposure on the human intestinal microbiota. Microbiology 156:3216-3223.

5. Claesson, M.J., S. Cusack, O. O’Sullivan, R. Greene-Diniz, H. de Weerd, E. Flannery, J.R. Marchesi, D. Falush, T. Dinan, G. Fitzgerald, C. Stanton, D. van Sinderen, M. O'Connor, N. Harnedy, K. O’Connor, C. Henry, D. O'Mahony, A.P. Fitzgerald, F. Shanahan, C. Twomey, C. Hill, R.P. Ross, and P.W. O'Toole. 2011. Composition, variability, and temporal stability of the intestinal microbiota of the elderly. Proc. Natl. Acad. Sci. U. S. A. 108 Suppl 1:4586-4591.

6. Fouhy, F., C.M. Guinane, S. Hussey, R. Wall, C.A. Ryan, E.M. Dempsey, B. Murphy, R.P. Ross, G.F. Fitzgerald, C. Stanton, and P.D. Cotter. 2012. High-throughput sequencing reveals the incomplete, short-term recovery of infant gut microbiota following parenteral antibiotic treatment with ampicillin and gentamicin. Antimicrob. Agents Chemother. 56:5811-5820.

7. Forslund, K., S. Sunagawa, J.R. Kultima, D.R. Mende, M. Arumugam, A. Typas, and P. Bork. 2013. Country-specific antibiotic use practices impact the human gut resistome. Genome Res. 23:1163-1169.

8. Pérez-Cobas, A.E., M.J. Gosalbes, A. Friedrichs, H. Knecht, A. Artacho, K. Eismann, W. Otto, D. Rojo, R. Bargiela, M. von Bergen, S.C. Neulinger, C. Däumer, F.A. Heinsen, A. Latorre, C. Barbas, J. Seifert, V.M. dos Santos, S.J. Ott, M. Ferrer, and A. Moya. 2013. Gut microbiota disturbance during antibiotic therapy: a multi-omic approach. Gut 62:1591-1601.

9. Illumina. Available at www.illumina.com/content/dam/ illumina-support/documents/documentation/chemistry_ documentation/16s/16s-metagenomic-library-prep-guide15044223-b.pdf

10. Wang, Q., Garrity, G.M., Tiedje, J.M., and J.R. Cole. 2007. Naïve Bayesian classifier for rapid assignment of rRNA sequences into the new bacterial taxonomy. Appl. Environ. Micro. 73:5261-5267.

11. Caporaso, J.G., J. Kuczynski, J. Stombaugh, K. Bittinger, F.D. Bushman, E.K. Costello, N. Fierer, A.G. Peña, J.K. Goodrich, J.I. Gordon, G.A. Huttley, S.T. Kelley, D. Knights, J.E. Koenig, R.E. Ley, C.A. Lozupone, D. McDonald, B.D. Muegge, M. Pirrung, J. Reeder, J.R. Sevinsky, P.J. Turnbaugh, W.A. Walters, J. Widmann, T. Yatsunenko, J. Zaneveld, and R. Knight. 2010. QIIME allows analysis of high-throughput community sequencing data. Nat. Methods 7:335-336. 
12. Parks, D.H., G.W. Tyson, P. Hugenholtz, and R.G. Beiko. 2014. STAMP: statistical analysis of taxonomic and functional profiles. Bioinformatics 30:3123-3124.

13. Zhu, Y.G., T.A. Johnson, J.Q. Su, M. Qiao, G.X. Guo, R.D. Stedtfeld, S.A. Hashsham, and J.M. Tiedje. 2013. Diverse and abundant antibiotic resistance genes in Chinese swine farms. Proc. Natl. Acad. Sci. U. S. A. 110:3435-3440.

14. Livak, K.J., and T.D. Schmittgen. 2001. Analysis of relative gene expression data using real-time quantitative PCR and the 2(-delta delta C(T)) method. Methods 25:402-408.

15. Stedtfeld, R.D., T.M. Stedtfeld, K.A. Fader, M.R. Williams, P. Bhaduri, J. Quensen, T.R. Zacharewski, J.M. Tiedje, and S.A. Hashsham. 2017. TCDD influences reservoir of antibiotic resistance genes in murine gut microbiome. FEMS Microbiol. Ecol. 93:fix058.

16. Martinez, J.L., T.M. Coque, and F. Baquero. 2015. What is a resistance gene? Ranking risk in resistomes. Nat. Rev. Microbiol. 13:116-123.

17. Lloyd-Price, J., G. Abu-Ali, and C. Huttenhower. 2016. The healthy human microbiome. Genome Med. 8:51.

18. Pehrsson, E.C., P. Tsukayama, S. Patel, M. Mejía-Bautista, G. Sosa-Soto, K.M. Navarrete, M. Calderon, L. Cabrera, W.
Hoyos-Arango, M.T. Bertoli, D.E. Berg, R.H. Gilman, and G. Dantas. 2016. Interconnected microbiomes and resistomes in low-income human habitats. Nature 533:212-216.

19. Turnbaugh, P.J., R.E. Ley, M. Hamady, C.M. FraserLiggett, R. Knight, and J.I. Gordon. 2007. The human microbiome project. Nature 449:804-810.

20. Finegold, S.M., Sutter, V.L., and G.E. Mathison. 1983. Normal indigenous intestinal flora. In D.J. Hentges (ed.), Human intestinal microflora in health and disease. Academic Press, Inc., New York, pp. 3-31.

Address correspondence to:

Fiona Walsh, PhD

Department of Biology

Maynooth University Main Street

Maynooth, Co-Kildare

W23F2H6

Ireland

E-mail: fiona.walsh@nuim.ie 